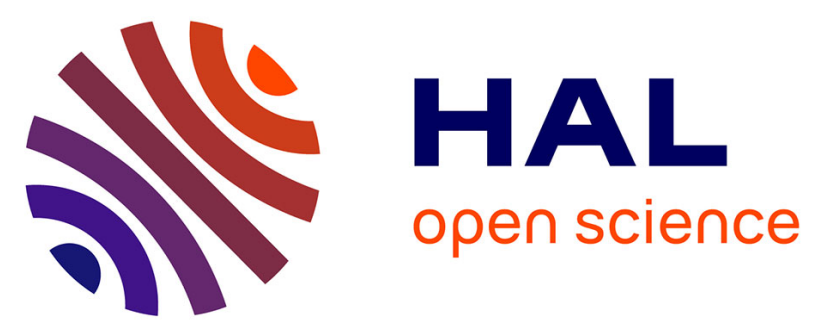

\title{
Pilot-Scale Investigation of Liquid Aluminum Filtration through Ceramic Foam Filters: Comparison between Coulter Counter Measurements and Metallographic Analysis of Spent Filters
}

Hervé Duval, Carlos Rivière, Émilie Laé, Pierre Le Brun, Jean-Bernard Guillot

\section{To cite this version:}

Hervé Duval, Carlos Rivière, Émilie Laé, Pierre Le Brun, Jean-Bernard Guillot. Pilot-Scale Investigation of Liquid Aluminum Filtration through Ceramic Foam Filters: Comparison between Coulter Counter Measurements and Metallographic Analysis of Spent Filters. Metallurgical and Materials Transactions B, 2009, 40 (2), pp.233-246. 10.1007/s11663-008-9222-y . hal-01240897

\author{
HAL Id: hal-01240897 \\ https://hal.science/hal-01240897
}

Submitted on 10 Dec 2015

HAL is a multi-disciplinary open access archive for the deposit and dissemination of scientific research documents, whether they are published or not. The documents may come from teaching and research institutions in France or abroad, or from public or private research centers.
L'archive ouverte pluridisciplinaire HAL, est destinée au dépôt et à la diffusion de documents scientifiques de niveau recherche, publiés ou non, émanant des établissements d'enseignement et de recherche français ou étrangers, des laboratoires publics ou privés. 


\title{
Pilot-Scale Investigation of Liquid Aluminum Filtration through Ceramic Foam Filters: Comparison between Coulter Counter Measurements and Metallographic Analysis of Spent Filters
}

\author{
HERVÉ DUVAL, CARLOS RIVIÈRE, ÉMILIE LAÉ, PIERRE LE BRUN, \\ and JEAN-BERNARD GUILLOT
}

\begin{abstract}
A pilot has been designed to study the mechanisms associated with liquid aluminum filtration through ceramic foam filters (CFFs). Before entering the filtering bowl, the liquid metal is seeded with massive artificial inclusions. A theoretical analysis of the filtration of massive inclusions shows that there are two preponderant deposition mechanisms, i.e., direct interception and sedimentation, which explain qualitatively the effect of the operating conditions on the measured filtration efficiency. Furthermore, it is observed that the filtration efficiency measured by two Coulter counters reaches a minimum value for a diameter close to $30 \mu \mathrm{m}$. This nonmonotonous trend can be explained by the coexistence of two populations of inclusions, intentionally added massive ones and oxide films. It is expected that oxide films are the most numerous inclusion type for diameters less than $25 \mu \mathrm{m}$ and have an apparent volume much larger than their absolute volume (contrary to massive inclusions), leading to a higher filtration efficiency. In addition, a metallographic analysis of spent filters shows that the density of the captured massive inclusions decreases exponentially between the filter inlet and the filter outlet. The initial filter coefficient can be derived, which is equal to $25 \mathrm{~m}^{-1}$ for a 30-ppi filter grade (with a specific surface area of $1610 \mathrm{~m}^{-1}$ ), $\mathrm{SiC}$ inclusions $50 \mu \mathrm{m}$ in diameter, and a filtration velocity of $0.9 \mathrm{~cm} \cdot \mathrm{s}^{-1}$.
\end{abstract}

DOI: $10.1007 / \mathrm{s} 11663-008-9222-\mathrm{y}$

(C) The Minerals, Metals \& Materials Society and ASM International 2009

\section{INTRODUCTION}

THE presence of inclusions in aluminum alloys adversely affects the quality and properties of aluminum products in many different ways. This is detrimental to the fatigue strength of aluminum alloys used specifically in the automotive and aeronautic industry. The presence of inclusions also results in defects that occur during processing operations: $:^{[1-3]}$ stringers on rolled products (for high-hardness inclusions), decohesion on forged products, and tearoff during forming with high plastic deformation (extrusion, rolling, and beverage-can-drawing processes). In the can industry, the constraints imposed with respect to the inclusion content are drastic: the inclusion concentration must be less than $10^{-4}$ parts per million (weight), to meet can producer requirements; this typically corresponds to much less than 20 defects per million cans produced. A case of

HERVÉ DUVAL, Associate Professor, and JEAN-BERNARD GUILLOT, Professor and Director, are with the Chemical and Material Engineering Laboratory, École Centrale Paris, ChâtenayMalabry 92290, France. Contact e-mail: herve.duval@ecp.fr CARLOS RIVIÈRE, formerly Doctoral Student, Rio Tinto Alcan Voreppe R\&D Center, is Development Engineer, La Metro-Communauté d'agglomération de Grenoble, Grenoble 38000, France. ÉMILIE LAÉ, Research Engineer, and PIERRE LE BRUN, R\&D Senior Engineer, are with the Rio Tinto Alcan Voreppe R\&D Center, Voreppe 38340 , France.

Manuscript submitted April 8, 2008. tearoff due to a fibrous refractory shot is shown in Figure 1.

The elimination of inclusions is particularly critical in the case of liquid aluminum. Although efforts have been undertaken to reduce the inclusion concentration, the high reactivity of liquid aluminum and the presence of refractory material necessarily result in new inclusions being formed in liquid metal, from the melt-processing stage through the casting into semifinished products.

Inclusions are classified as endogenous or exogenous, according to their origin. Endogenous inclusions are formed in situ as a result of the chemical reactions of the liquid metal (e.g., the formation of surface oxides). Exogenous inclusions originate from the external medium and penetrate the liquid metal. Such inclusions may consist of pieces of refractory material from furnaces or troughs.

In numerous industrial applications, liquid aluminum filtration supplements other processes aimed at eliminating impurities (the settling of inclusions in a holding furnace and flotation in degassing ladles).

One distinguishes between two modes of liquid metal filtration: cake-type filtration, in which suspended particles greater in size than that of the filter pores, deposit at the filter inlet and form a cake of growing thickness, which constitutes the actual filtering medium, and depth filtration, in which suspended particles are smaller in size than the filter pores and, therefore, enter the filter and deposit within the filter (thus causing gradual clogging of the filter). The filters used in today's 


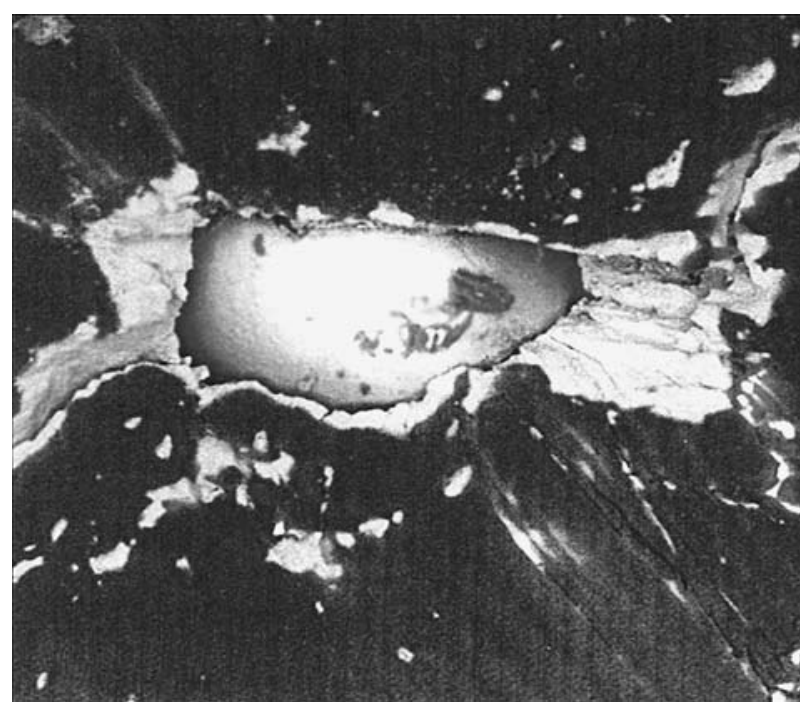

Fig. 1-Tearoff due to an exogenous inclusion (fibrous refractory shot).

aluminum cast shops are designed to prefer use of the depth filtration mode.

It should be noted that alternatives to filtration are under development at present; these include cyclone, ${ }^{[4-6]}$ electromagnetic sedimentation techniques, ${ }^{[7-11]}$ and ultrasonic treatment in the cavitation field. ${ }^{[12]}$ However, most of these techniques are not as yet industrially viable.

Three types of filters have been developed for liquid aluminum depth filtration: the rigid media filter, ${ }^{[13,14]}$ the granular bed (a deep bed filter (DBF)), and the ceramic foam filter (CFF). The latter two devices are most commonly used for liquid aluminum filtration.

The development of the DBF was initiated by Brondyke and Hess in 1964. ${ }^{[15]}$ The filter medium typically consists of tabular alumina (a few millimeters in diameter) with large alumina balls at the top and bottom of the filter. ${ }^{[16]}$ The length of the tabular alumina filter bed is typically between 20 and $50 \mathrm{~cm}$. The filtration speed is of the order of a few millimeters per second (1 to $4 \mathrm{~mm} / \mathrm{s}$, according to Reference 17). As a consequence, the liquid metal residence time in the filter is high. The DBFs are known to be very efficient ${ }^{[17]}$ and their lifetimes are long.

In 1974, CFFs were developed for the filtration of molten aluminum. The first commercial application of CFFs started in 1976 at Alcan's sheet mill facility in Oswego, NY. ${ }^{[18]}$ Today, CFFs are used in more than 50 pct of the wrought aluminum cast in the world. ${ }^{[19]}$ The CFFs are in the form of tiles. They are essentially manufactured via the "foam replication" technique. ${ }^{[19]}$ In this process, polyurethane foam is coated with ceramic slurry and the resulting part is dried and fired. During firing, the polyurethane foam within the ceramic coating vaporizes and exits the structure, leaving behind the porous ceramic (phosphate-bonded alumina, for example) foam. Tile sizes range from $18 \mathrm{~cm}$ to $66 \mathrm{~cm} ; 5 \mathrm{~cm}$ is the standard thickness. The filtration speed is typically between 0.6 and $1.6 \mathrm{~cm} / \mathrm{s} .{ }^{[17]}$ The liquid metal residence time in the CFF is much lower than in the DBF. The CFFs are generally less efficient than the DBFs and their lifetimes are shorter. On the other hand, CFFs are inexpensive and easy to use compared to DBFs. ${ }^{[20]}$

The present investigation will focus on CFFs.

Ceramic foam filters have been extensively studied in the literature. Three main techniques are used to evaluate their performance: porous disk filtration analysis (PoDFA), liquid aluminum inclusion sampler (LAIS), and liquid metal cleanliness analyzer (LiMCA). The PoDFA and LAIS techniques are off-line techniques in which a fixed volume of metal is forced through a sampling filter, concentrating the inclusions. Subsequent metallographic analysis of the sampling filter is performed to measure the amount and type of inclusions present. The LiMCA technique is a Coulter counter specifically developed for liquid metals. It measures both the amount and the size distribution of the inclusions. These techniques can be supplemented by metallographic observations of spent filters.

The present review will principally focus on LiMCA measurements and metallographic observations, because they are the two techniques used for this study.

The overall filtration efficiency, here denoted $E$, is the usual evaluation criterion for the CFF. It is often based on $N 20$ (sometimes on N15), the average number of inclusions larger than $20 \mu \mathrm{m}$ (or $15 \mu \mathrm{m}$, respectively) per kilogram of aluminum alloy (N20 is given in thousands of inclusions per kilogram of liquid metal, i.e., $\mathrm{k} / \mathrm{kg}$ ). Hence, $E$ (in percent) is defined by

$$
E=\frac{N 20_{i}-N 20_{o}}{N 20_{i}} \times 100
$$

where $N 20_{i}$ (or $N 20_{o}$ ) is the average number of inclusions larger than $20 \mu \mathrm{m}$ per kilogram of aluminum alloy at the filter inlet (or outlet, respectively) measured by LiMCA.

Figure 2 gives a summary of the filtration efficiency evaluated by LiMCA measurements before and after the filter, as a function of the filter commercial grade (number of pores per linear inch specified by the manufacturer) and the filtration parameters (filtration velocity and alloy) reported in previous articles. ${ }^{[21-28]}$ The filtration velocity is defined by Eq. [2]:

$$
u_{s}=\frac{Q_{m}}{\rho S}
$$

where $Q_{m}$ is the mass flow rate, $\rho$ the molten aluminum density, and $S$ the filter surface.

As can be seen, the CFF averaged efficiencies reported in the literature are spread over a wide range, i.e., from 30 to 90 pct. These discrepancies can be partially explained by variations in the filtration parameters. They can be classified according to the filter parameters (pore size and chemistry), the inclusion parameters (nature, size, and number), and the process parameters (alloy, use of grain-refining rod, filtration velocity, and upstream treatment).

It has been experimentally shown that the filtration efficiency increases when the pore size decreases or, equivalently, when the grade increases (for filters coming 


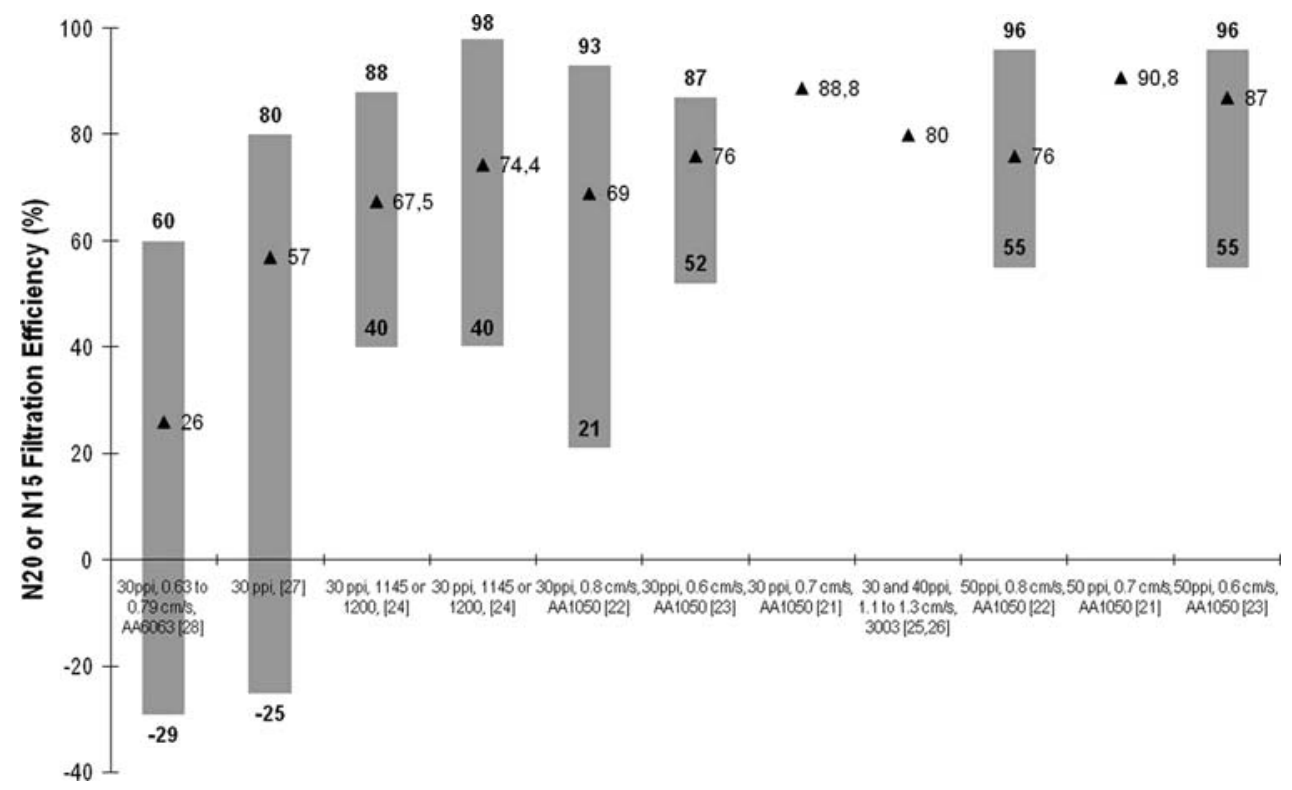

Fig. 2-Filtration efficiencies (Refs. 22 and 23: measured on N15, the remainder: on N20) reported in the literature as a function of the filter grade. Range (in gray), mean value (triangle).

from the same manufacturer)..$^{[1,21-25,29]}$ The filtration efficiency measured for a given inclusion size (the width of the size interval is usually 5 to $10 \mu \mathrm{m}$ ) is generally higher for larger inclusions. ${ }^{[2,21-24,29]}$ However, some authors ${ }^{[24,28]}$ have noticed a decrease in the filtration efficiency for inclusion sizes of approximately $50 \mu \mathrm{m}$. They attributed this tendency to the capture, aggregation, and subsequent release of the inclusions in the CFF.

It is also experimentally established that an increase in the filtration velocity decreases the filtration efficiency, ${ }^{[1,16,28,30]}$ and some brutal variations in the filtration velocity can cause the release of inclusions. ${ }^{[28]}$ The use of a grain-refining rod at the filter inlet was shown to decrease the filtration efficiency; the effect was significant in the case of high inclusion loading ( $N 15$ of approximately $10 \mathrm{k} / \mathrm{kg}){ }^{[27,28]}$

Assuming that the suspended inclusion concentration profile throughout the filter can be described by the logarithmic law ${ }^{[33]}$ it is relevant to define the filter coefficient $\lambda$ according to the following relation:

$$
\lambda=-\ln (1-E) / L
$$

where $L$ is the depth of the filter. The filter coefficient can then easily be expressed in terms of the filtration parameters just introduced. This approach, originally developed as part of the granular filtration of hydrosols, ${ }^{[33,34]}$ has been applied to liquid metal depth filtration $^{[16]}$ and, in particular, to liquid aluminum filtration through the CFF. ${ }^{[1,27,30,35,36]}$ It has been found that the dependence of the filter coefficient on the filtration velocity (in the case of liquid aluminum depth filtration) is consistent with the dependence reported in Tien's book. ${ }^{[34]}$ For a 30-ppi CFF with intentionally added $\mathrm{TiB}_{2}$ inclusions (in sizes ranging from 2 to $8 \mu \mathrm{m}$ ), the filter coefficient varies between 10 to $2 \mathrm{~m}^{-1}$ when the filtration velocity increases from 2 to $20 \mathrm{~mm} \cdot \mathrm{s}^{-1} \cdot{ }^{[30]}$ Tian and Guthrie ${ }^{[35]}$ reported filter coefficient values equal to approximately $40 \mathrm{~m}^{-1}$ for a 30 -ppi CFF with alumina inclusions between 40 and $60 \mu \mathrm{m}$ in size.

It should be noted that the logarithmic law has been validated for the granular filtration of hydrosol (in particular, by locally measuring the suspended particle concentration in sand beds ${ }^{[33]}$ ); to our knowledge, however, there is no experimental evidence that the suspended inclusion concentration profile throughout a CFF can be described by the logarithmic law.

Most experimental studies on liquid aluminum filtration include some observations of spent filters. $^{[1,2,18,20-25,29,35,36]}$

Several articles ${ }^{[2,18,25,36]}$ showed that the inclusion content was decreasing in quantity from the top to the bottom of the filter. These observations are consistent with the depth filtration mechanism generally advanced in the literature ${ }^{[18,24,28-30,35,36]}$ for the CFF.

The clustering of inclusions across the ceramic foam windows in the uppermost part of the filter and the subsequent formation of bridges were also evidenced. $^{[18,21-25,29,31,32,36]}$ Some authors ${ }^{[31,32]}$ have noticed that bridges are more numerous when the filter is fine (a grade larger than $50 \mathrm{ppi}$ ) and when there is no grain refiner (TiBAl or TiCAl) added. The presence of such bridges in spent filters has been related to high values of filtration efficiency. ${ }^{[21-23,31,32]}$ It is thought that the bridges induce a kind of cake filtration. For current industrial filtration conditions (an inclusion level lower than $1 \mathrm{ppm}$ and a filtration velocity lower than $20 \mathrm{~mm} \cdot \mathrm{s}^{-1}$ ), such cake filtration does not lead to premature blocking of the filter (encountered when the inclusion content of the melt is high).

In order to study and quantify the mechanisms acting in liquid aluminum filtration through a CFF, a filtration pilot has been developed. ${ }^{[37,38]}$ Filtration experiments 
have been coupled to Coulter counter measurements or to the metallographic analysis of nondrained spent filters.

The results provided by both techniques will be analyzed. In particular, the spatial distribution of inclusions in the filter will be derived from the metallographic observations, and the relevant capture sites will be identified. Finally, the filtration efficiencies and filter coefficients derived from both techniques will be compared and discussed.

\section{EXPERIMENTAL SETUP}

The filtration pilot is represented in Figure 3. It is made of a resistance tilting furnace, a launder system, a second resistance furnace, and a metal recuperation ladle. The $\mathrm{CFF}$ is cut into cylinders to fit into a refractory mold set in the second resistance furnace. Two filter diameters have been used, i.e., 5 and $10 \mathrm{~cm}$. The casting line is instrumented with three thermocouples, the first one before the filter, the second one after the filter, and the third one on the tile.

The experimental procedure is as follows. The aluminum ingots are melted in the tilting furnace. The metallic bath is held at $750{ }^{\circ} \mathrm{C}$. The filter is preheated and impregnated with liquid metal. The melt is artificially seeded with inclusions and homogenized. The cast then starts.

It should be noted that, as the liquid aluminum enters the filtering bowl, it contains two kinds of inclusions:

(a) exogenous inclusions, essentially intentionally added ones, introduced into the tilting furnace; and

(b) endogenous inclusions, such as oxide films that form as soon as the liquid aluminum is in contact with air.

The metal is regularly poured into the launder, through the filter, and to the recuperation ladle. The metal flow rate is continuously measured using a balance placed under the recuperation ladle. The thermal conditions were reproducible. For the molten metal characterization, LiMCAs are used before and after the filter.

At the end of a cast, the metal solidifies in the filter. The tile can then be cut for metallographic observations of the inclusions.

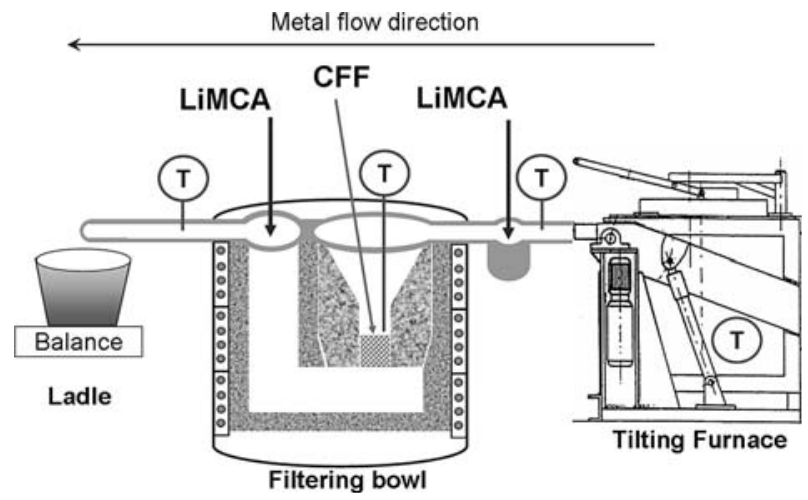

Fig. 3-Filtration pilot block diagram.
The first advantage of this experimental setup is the fact that the metal can calmly solidify in the filter, which prevents the inclusions from release and spatial redistribution. Indeed, for most industrial CFFs, the tile is drained of metal after the cast and the liquid metal/ oxide skin/air interface that crosses the filter during the drainage probably modifies the inclusion distribution. Furthermore, the tile undergoes shocks as is it removed from its seat, which is also thought to create inclusion detachments. In the experimental setup, however, the inclusions present in the tile stay where they were trapped. The tile can then be cut lengthwise and transversally for metallographic observations of the inclusions at various depths.

The second advantage is that proper LiMCA measurements can be done before and after the filter. In most plants, this type of measurement does not give the right inclusion concentration in molten metal, because the degassing treatment occurs just before the CFF. The microbubbles present in molten metal are seen by the LiMCA as inclusions. The use of an extension probe or measuring during the pressure cycle is supposed to reduce the volume of gas bubbles seen by the LiMCA. However, it was shown that these two techniques underestimate the inclusion concentration, and the problem of interpreting the LiMCA particle count in the presence of microbubbles is still unresolved. ${ }^{\text {[39] }}$ Consequently, by decoupling the filtration from the degassing treatment, this experimental setup permits more reliable evaluation of the CFF filtration efficiency.

\section{RESULTS}

The results relative to the characterization of the filters and the CFF depth filtration experiments are reported in this section.

\section{A. Characterization of the Filters}

Three filter tiles, denoted A, B, and C, have been used for the trials reported in the present article. The three tiles are alumina based. They come from three different suppliers. The grade of tiles $\mathrm{A}$ and $\mathrm{C}$ is equal to $30 \mathrm{ppi}$; the grade of tile $\mathrm{B}$ is equal to $50 \mathrm{ppi}$.

The structure of the filter tiles has been characterized as follows: the porosity has been measured by immersion and the connexity number by unit of length has been obtained through analysis of the images of the ground sections of the filter samples previously filled with resin. The specific surface area has been derived from the connexity number per unit of length, using the appropriate stereometric relation. The data are reported in Table I: the geometric characteristics of the filter tiles chosen in the present article are relatively close to each other, although their commercial grades can be different.

It should be noted that a fraction of the measured porosity associated with the template of the polymer foam (as used in the production of the CFF) is not accessible to liquid metal. It is difficult to quantify this porosity fraction precisely by image analysis, because 
the measurement strongly depends on the binarization threshold. However, this porosity could be removed before estimating the connexity number by image analysis. The analysis of the filter samples by X-ray microtomography (carried out at the European Synchrotron Radiation Facility, Grenoble, France) specifically allows the measurement of both the porosity accessible to liquid metal and the related specific surface area. This analysis has been performed for filter tile C; the porosities accessible to the liquid metal and the related specific surface area have been estimated at 79 pct and $1610 \mathrm{~m}^{-1}$, respectively. The value of the specific surface area estimated from X-ray microtomography is in good agreement with the value provided by stereometry.

\section{B. Coulter Counter Measurements}

Coulter counter measurements associated with three trials are presented here. The operating conditions and the main results are summarized in Table II. In the reported trials, a 5182 alloy has been used. The filter diameter is equal to $10 \mathrm{~cm}$. In the first trial, the filter cylinder has been cut in CFF tile $\mathrm{A}$; in the second and third trials, the filter cylinder has been cut in CFF tile B. In the first trial, denoted $\mathrm{A}$, the filtration velocity is equal to $1.3 \mathrm{~cm} \cdot \mathrm{s}^{-1}$; in the second trial, $\mathrm{B} 1$, and third trial, $\mathrm{B} 2$, it is equal to $1.8 \mathrm{~cm} \cdot \mathrm{s}^{-1}$.

The liquid metal is artificially seeded with aluminabased inclusions. The LiMCA permits a determination of the particle size distribution of the suspended inclusions in liquid aluminum at the filter inlet. The numbers $N 20, N 40$, and $N 60$ of inclusions (per kilogram of liquid metal) of a mean diameter greater than 20, 40, and $60 \mu \mathrm{m}$, respectively, measured at the tilting furnace exit after seeding are approximately 50,5 , and $1 \mathrm{k} / \mathrm{kg}$, respectively.

According to Reference 29, which distinguishes three inclusion levels (low range $<1 \mathrm{k} / \mathrm{kg}, \quad 1 \mathrm{k} / \mathrm{kg}<\mathrm{mid}$ range $<10 \mathrm{k} / \mathrm{kg}$, and high range $>10 \mathrm{k} / \mathrm{kg}$ ), tests $\mathrm{A}$, $\mathrm{B} 1$, and $\mathrm{B} 2$ have been performed with a high inclusion

Table I. Geometric Characteristics of Filter Tiles Used in Present Article

\begin{tabular}{llll}
\hline Filter Tile & \multicolumn{1}{c}{ A } & \multicolumn{1}{c}{ B } & \multicolumn{1}{c}{ C } \\
\hline Commercial grade (ppi) & 30 & 50 & 30 \\
Porosity (pct) & $87 \pm 1$ & $89 \pm 1$ & $88 \pm 1$ \\
$\begin{array}{l}\text { Connexity number per unit } \\
\quad \text { of length }\left(\mathrm{m}^{-1}\right)\end{array}$ & 320 & 370 & 375 \\
Specific surface area $\left(\mathrm{m}^{-1}\right)$ & 1280 & 1480 & 1500 \\
\hline
\end{tabular}

loading. However, it should be noted that the inclusion level of the incoming metal remains much lower than the levels that lead to premature blocking of the filter. Indeed, metallographic analysis of the spent filters shows that, in tests $\mathrm{A}, \mathrm{B} 1$, and $\mathrm{B} 2$, filters operate in the so-called initial stage of depth filtration (the deposition of inclusions inside the filter remains small, so that the filter performance can be regarded as the performance of the original filter, i.e., the clean filter).

The evolution of the N20 number at the filter inlet and outlet is shown in Figures 4 and 5 against tests $A$ and

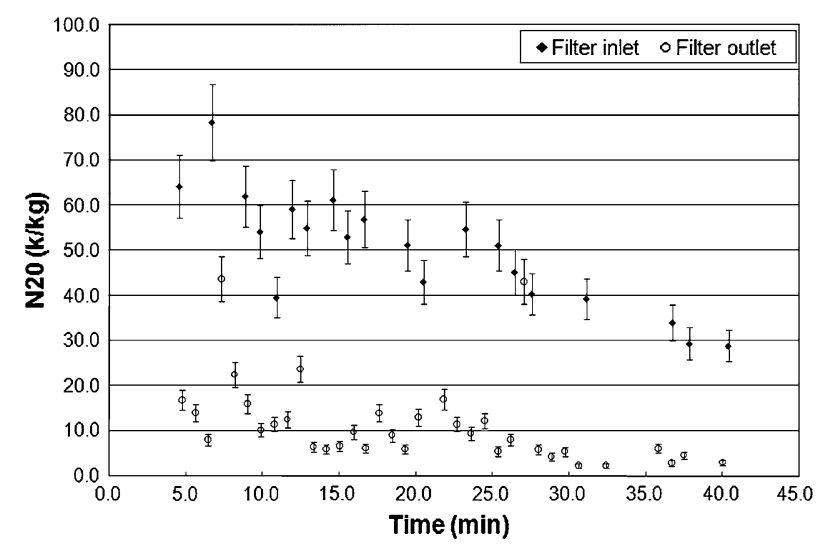

Fig. 4-Number $N 20$ of inclusions with a mean diameter over $20 \mu \mathrm{m} / \mathrm{kg}$ of liquid metal at filter inlet and outlet, measured by LiMCA (test A, 30-ppi grade, 5182 alloy, seeding with alumina-based inclusions, filtration velocity $1.3 \mathrm{~cm} \cdot \mathrm{s}^{-1}$ ).

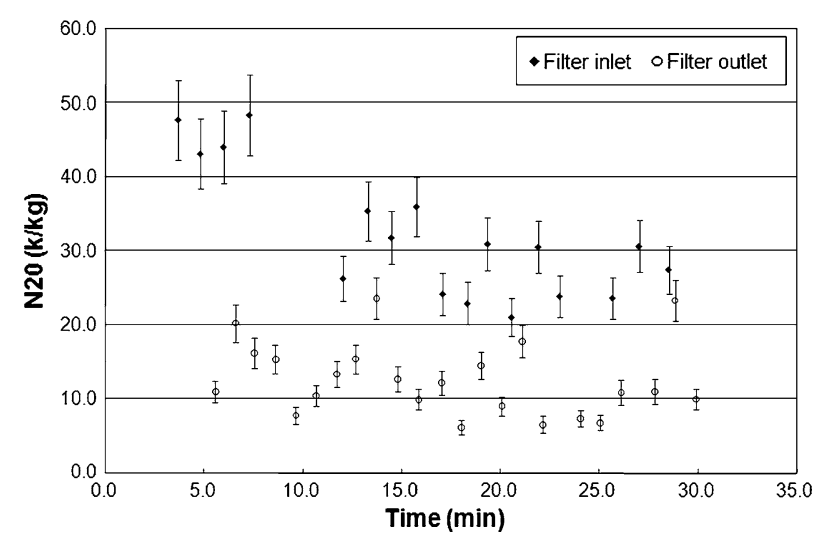

Fig. 5-Number $N 20$ of inclusions with a mean diameter over $20 \mu \mathrm{m} / \mathrm{kg}$ of liquid metal at filter inlet and outlet measured by LiMCA (test B1, 50-ppi grade, 5182 alloy, seeding with alumina-based inclusions, filtration velocity $1.8 \mathrm{~cm} \cdot \mathrm{s}^{-1}$ ).

Table II. Trials A, B1, and B2: Operating Parameters, Mean Number $\mathrm{N20}_{i}\left(\right.$ or $\left.\mathrm{N20}_{o}\right)$ of Inclusions with a Mean Diameter over $20 \mu \mathrm{m} / \mathrm{kg}$ of Liquid Metal Measured at Filter Inlet (or Outlet), and Filter Efficiency $E$

\begin{tabular}{|c|c|c|c|c|c|c|c|}
\hline Trial Identifier & Alloy & Filter Diameter $(\mathrm{cm})$ & Tile Supplier & $u_{s}\left(\mathrm{~cm} \cdot \mathrm{s}^{-1}\right)$ & $N 20_{i}(\mathrm{k} / \mathrm{kg})$ & $N 20_{o}(\mathrm{k} / \mathrm{kg})$ & $E(\mathrm{Pct})$ \\
\hline A & 5182 & 10 & A & 1.3 & 50 & 11 & 77 \\
\hline B1 & 5182 & 10 & B & 1.8 & 32 & 13 & 61 \\
\hline B2 & 5182 & 10 & B & 1.8 & 33 & 13 & 60 \\
\hline
\end{tabular}


B1, respectively. It should be noted that the evolution of the $N 20$ at the filter inlet is similar to that observed in industrial plants. Initially, the $N 20$ decreases due to the settling of inclusions in the tilting furnace. Next, at the end of the cast, when the furnace is emptied, the $N 20$ increases due to the release of settled inclusions. This last phase, which corresponds to an increase in the $N 20$ at the filter inlet, has actually been observed in the course of tests A and B1. However, it is not shown in Figures 4 and 5 , because it occurred when the filtration velocity was no longer constant.

In trials $\mathrm{A}, \mathrm{B} 1$, and $\mathrm{B} 2$, the average filtration efficiencies based on the $N 20$ and calculated from the LiMCA measurements are equal to $77 \pm 4$ pct, $61 \pm 8$ pct, and $60 \pm 8$ pct, respectively. These efficiencies are within the efficiency range measured in industrial plants and reported in Figure 2. A comparison between the filter efficiencies measured in tests B1 and B2 (characterized by the same operating conditions) shows that the repeatability of the experimental setup is satisfactory. It is also interesting to note that, despite the finer grade, the efficiency is lower for the 50-ppi filter (trials B1 and B2). Although the inclusion concentration of the incoming metal is different in test $\mathrm{A}$ and in tests B1 and B2 (Table II), this cannot explain the discrepancy between the filtration efficiencies measured in test $\mathrm{A}$ and in tests B1 and B2. Indeed, an increase in the inclusion concentration at the filter inlet usually leads to a decrease in the filtration efficiency (when cake filtration is absent, which is the present case), and an increase in the filtration efficiency is actually observed. This point will be further discussed in Section IV.

Figure 6 shows the filter coefficient variations as a function of the inclusion diameter (associated with the sphere having the same volume as the inclusion). The filter coefficient is given for growing width intervals, in order to minimize uncertainty. Indeed, the number of inclusions per kilogram of liquid metal that have a diameter larger than a given boundary value decreases with an increasing boundary value; the statistical dispersion of the LiMCA, however, increases with a decreasing number of inclusions per kilogram of liquid metal. It is observed that the filter coefficient is high for low diameter values (close to $20 \mu \mathrm{m}$ ), decreases with an

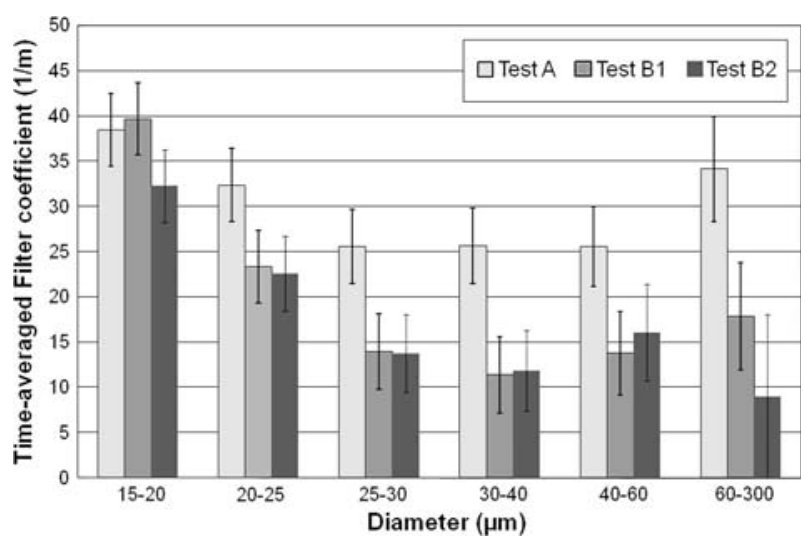

Fig. 6-Variations in filter coefficient as a function of inclusion diameter in tests $\mathrm{A}, \mathrm{B} 1$, and $\mathrm{B} 2$. increasing inclusion diameter, reaches a minimum for a diameter value close to $30 \mu \mathrm{m}$, and then slightly increases.

This nonmonotonous behavior, in particular, the surprising decrease in the filter coefficient, will be further analyzed in Section IV. Finally, a comparison of the filter coefficient variations measured in tests B1 and B2 confirms that the repeatability of the experimental setup is satisfactory.

\section{Metallographic Observations}

The metallographic observations of two spent filters are presented here. The filters come from two trials that differ from the trials A, B1, and B2 presented in Section B. The filters have been prepared to optimize the metallographic analysis and the inclusion statistics. The filter diameter is smaller and is equal to $5 \mathrm{~cm}$. The liquid metal is artificially seeded with silicon carbide inclusions, which are more easily identifiable on ground sections than are alumina-based inclusions. The trials have been conducted until filter clogging. In addition, in both trials, a 1080 alloy has been used, the filter cylinders have been cut in CFF tile $\mathrm{C}$, and the filtration velocity is equal to $0.9 \mathrm{~cm} \cdot \mathrm{s}^{-1}$. The two trials are hereafter referred to as $\mathrm{C} 1$ and $\mathrm{C} 2$.

The silicon carbide inclusions are massive, sharp angled, and hard, with a density of $3200 \mathrm{~kg} \cdot \mathrm{m}^{-3}$. Their particle size distribution prior to introduction into the liquid aluminum ranges from 25 to $100 \mu \mathrm{m}$; their number-related fractions over 40 and $60 \mu \mathrm{m}$ are approximately 75 and $50 \mathrm{pct}$, respectively; and the numberrelated mean diameter is $50 \mu \mathrm{m}$. According to Reference 40 , once immersed in aluminum, silicon carbide inclusions get covered with a thin alumina layer (i.e., the thin silica layer that covers the silicon carbide particles is reduced by the liquid aluminum, resulting in the formation of an alumina layer). Hence, the filtration behavior of a $\mathrm{SiC}$ inclusion should not be far from the behavior of an alumina-based one.

A detailed analysis of the two spent filters coming from trials $\mathrm{C} 1$ and $\mathrm{C} 2$ has been performed. In the case of the filter from test $\mathrm{C} 1,160$ successive transverse metallographic cuts of a quarter of a filter have been carried out and observed; in the case of the filter from test $\mathrm{C} 2$, 40 cuts were carried out and observed. Typical images (here from the filter used in test $\mathrm{C} 1$ ) are shown in Figures 7 and 8 . The metallographic cut displayed in Figure $7(100 \mu \mathrm{m}$ from the filter inlet) shows that the filter entrance is partially clogged, mainly by trapped oxide films; the metallographic cut displayed in Figure 8 $(2.2 \mathrm{~cm}$ from the filter inlet), however, shows that the bottom part of the filter is still in the initial stage of depth filtration. It should be remembered that, by definition, in the initial stage, the deposition of inclusions inside the filter remains small. Its effect on the properties of the filter is negligible, so that the performance of the filter can be regarded as the performance of the original filter, i.e., the clean filter.

On the basis of the observations from the metallographic cuts, one distinguishes between the following three capture configurations (Figure 9): 


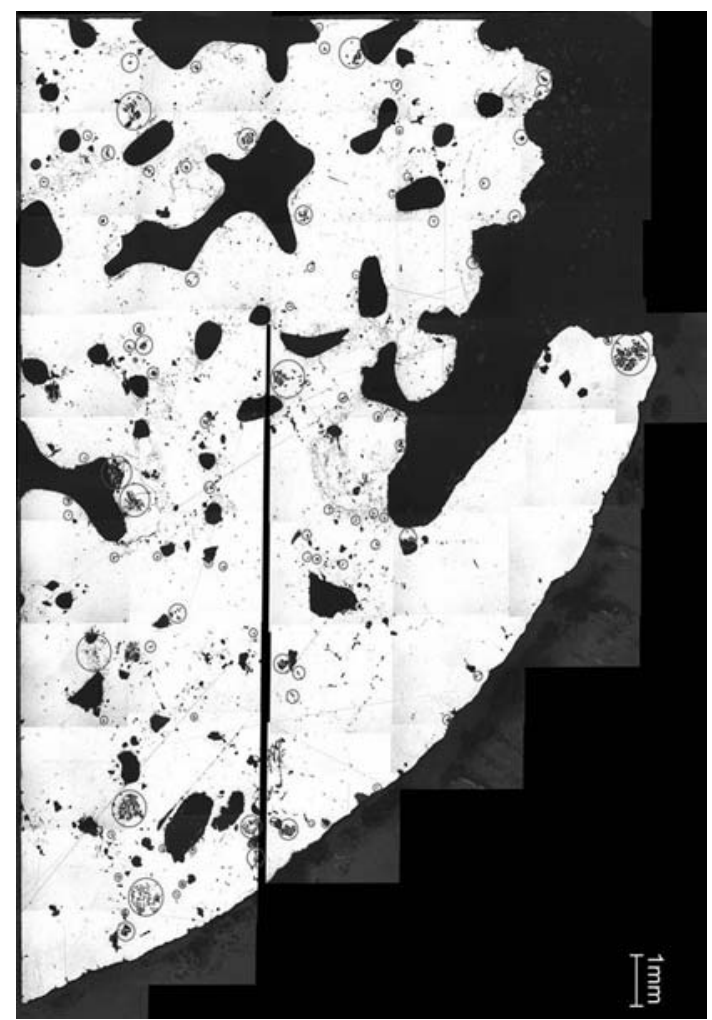

Fig. 7-Transverse metallographic cut of a quarter of the filter used in test $\mathrm{C} 1,100 \mu \mathrm{m}$ from the filter inlet.

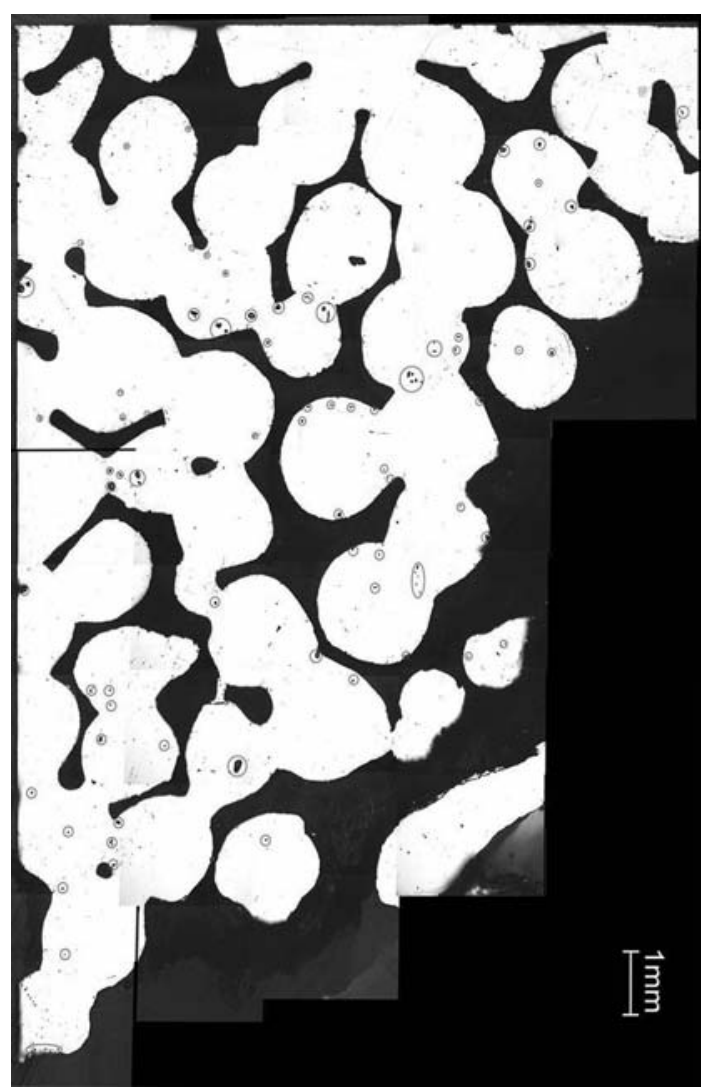

Fig. 8-Transverse metallographic cut of a quarter of the filter used in test $\mathrm{C} 1,2.2 \mathrm{~cm}$ from the filter inlet.
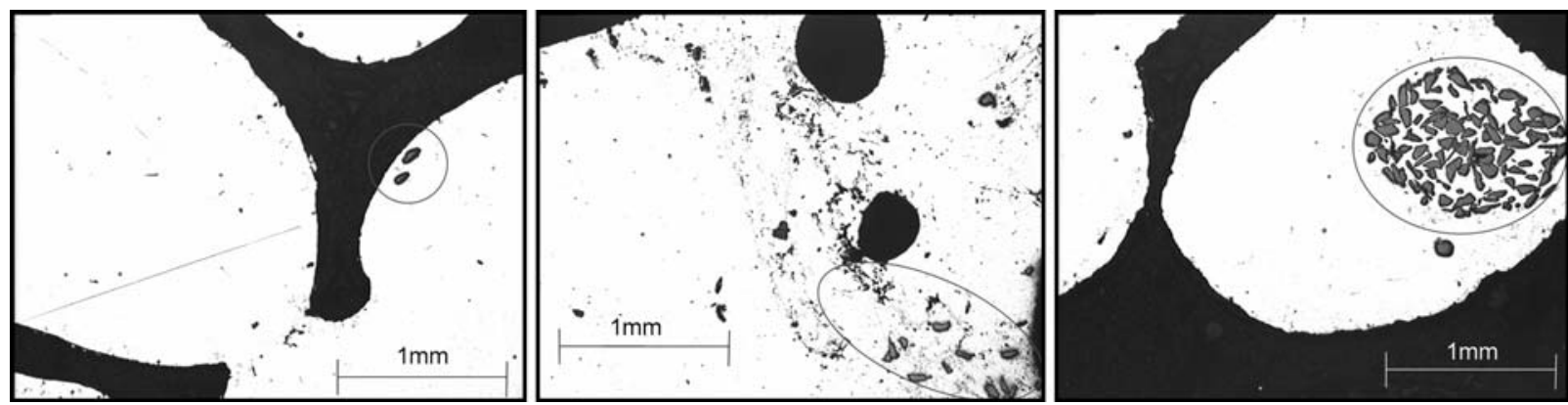

Fig. 9-Three capture configurations (black: ceramic, white: aluminum alloy, dark gray: inclusions): isolated massive inclusions (left), bridge (center), and aggregate (right).

(a) isolated $\mathrm{SiC}$ inclusions captured at the vicinity of the filter internal walls (capture configuration I);

(b) inclusions of $\mathrm{SiC}$ captured by bridges mainly made of tangled oxide films anchored on the filter walls (capture configuration II); and

(c) fairly dense and spherical aggregates of $\mathrm{SiC}$ inclusions captured by a filter wall or by a pore constriction (capture configuration III).

Capture configuration I can be found throughout the whole depth of the spent filters. The oxide bridges are essentially observed in the very first millimeters of the filter, where they are numerous and contribute significantly to the capture of $\mathrm{SiC}$ inclusions (capture configuration II). The dense and spherical aggregates of $\mathrm{SiC}$ inclusions (capture configuration III) are also primarily located at the filter entrance. However, some aggregates have been observed deeper in the filter. The aggregate size typically lies between a few hundred micrometers and $1 \mathrm{~mm}$. The analysis of the metal sampled after seeding but before filtration has permitted verification that the fairly dense and spherical aggregates of the $\mathrm{SiC}$ inclusions did not form inside the filter but before or during the seeding of liquid metal in the tilting furnace. The formation of aggregates of $\mathrm{SiC}$ 
particles in liquid aluminum has already been reported by Johansen and Taniguchi. ${ }^{[41]}$ For the smallest aggregates, shapeless and containing few inclusions, it is difficult to determine clearly how they are formed, i.e., upstream of the filter during seeding or in the filter by aggregation of individually captured inclusions. Such small aggregates are principally found at the filter inlet.

The SiC inclusions are then counted on each transverse cut of the filters used in tests $\mathrm{C} 1$ and $\mathrm{C} 2$. Figure 10 summarizes the counting data relative to the 160 successive transverse metallographic cuts carried out on a quarter of the filters used in test $\mathrm{C} 1$. More precisely, both the total number of inclusions counted on each metallographic cut and the number of inclusions captured individually is reported (the difference between the two curves corresponds to inclusions in the form of aggregates). Two regions are distinguished in the filter: the first, the initial $2 \mathrm{~mm}$ from the inlet (the top part of the filter), and the second, the remainder of the filter depth (the bottom part of the filter). Indeed, the density of trapped inclusions in the top part is excessively large compared to that in the bottom part. Approximately $2 \mathrm{~mm}$ from the filter inlet, corresponding to a depth of between one and two pores, the density of trapped inclusions falls abruptly and then slowly declines up to the filter outlet. The inclusions located in the top part of the filter are essentially incorporated into aggregates; configuration III is the main capture configuration. The total number of inclusions presents some peaks in the bottom part of the filter associated with the capture of some dense and spherical aggregates that could penetrate deeper into the filter. In addition, the density of the isolated inclusions trapped in the top part of the filter is much higher than that in the bottom part. Indeed, the capture of inclusions in the first $2 \mathrm{~mm}$ is enhanced by the partial clogging of the filter top part. Surprisingly, only 15 pct of the isolated $\mathrm{SiC}$ inclusions trapped in the filter are located in the first $2 \mathrm{~mm}$, whereas 85 pct are located in the rest of the filter. Thus, although the inclusion concentration in the top part of the filter is high, its contribution to the overall capture of isolated $\mathrm{SiC}$ inclusions (as opposed to $\mathrm{SiC}$ aggregates formed during seeding) seems to be minor, compared to the contribution of the bottom part.

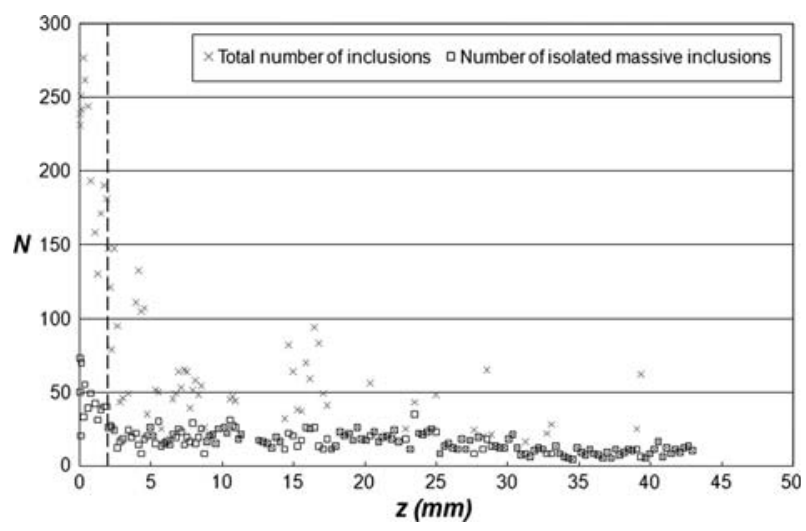

Fig. 10-Number $N$ of massive inclusions counted on a transverse metallographic cut of a quarter of the filter at depth $z$ from filter inlet vs depth $z$.

\section{DISCUSSION}

Initially, the preponderant capture mechanisms in liquid aluminum depth filtration will be identified and the scaling laws associated with the preponderant mechanisms ${ }^{[38]}$ will be used to interpret the filtration efficiencies (based on N20) measured in trials A, B1, and B2.

Next, the relative weights of the intentionally added massive inclusions and the oxide films in trials $\mathrm{C} 1$ and $\mathrm{C} 2$ will be quantified. This quantification will provide a key to explaining the decreasing character of the filtration efficiency variations as a function of the inclusion diameter (measured by LiMCA) in trials A, B1, and B2.

Finally, the filter coefficient will be determined in trials $\mathrm{C} 1$ and $\mathrm{C} 2$ from the captured $\mathrm{SiC}$ inclusion density profile (measured from successive transverse metallographic cuts of the filter). The value of the filter coefficient derived from the metallographic analysis will be compared to both the LiMCA measurements and an estimation provided by a computational fluid dynamics (CFD) simulation. ${ }^{[38]}$

\section{A. Preponderant Deposition Mechanisms}

There are six mechanisms for inclusion deposition through porous media: direct interception, inertial impaction, sedimentation, surface forces, Brownian diffusion, and straining. ${ }^{[34]}$ Inclusion deposition by direct interception occurs specifically because inclusions are finite in size: considering inclusions moving along liquid metal streamlines, any inclusion will be deposited that comes within one inclusion's radius from the filter inner wall. Because of their inertia, inclusions may deviate from the fluid streamlines, typically when fluid streamlines are changing direction near an obstacle. Some of the inclusion trajectories may then intersect the obstacle, leading to inclusion deposition; this mechanism is called inertial impaction. Inclusion deposition by sedimentation occurs when the inclusion density is different from that of the liquid metal: the inclusion will settle out in the direction of the gravitational force. Surface forces can affect inclusion trajectories and, consequently, provide a non-negligible contribution to inclusion transport. For inclusions of submicronic size, Brownian motion (arising from liquid metal atoms bombarding the inclusion surface) becomes significant and may contribute to the inclusion transport to the filter's inner walls; this mechanism is called Brownian diffusion. Finally, if the size of the inclusions present in the liquid metal is greater than the pore constriction of the filter, the inclusions will be retained in the filter the way inclusions are retained in a sieve, when the openings of the sieve are smaller than each inclusion diameter. This deposition mechanism is known as straining or sieving. ${ }^{[34]}$

To determine the preponderant deposition mechanisms in the present filtration experiments, a set of data (Table III) representative of the tests reported in this article is taken as a basis.

The values of the interception, Stokes, gravitational, London, and Péclet numbers associated with the mechanisms mentioned here are summarized in Table IV. 
Table III. Operating Conditions Representative of Aluminum Filtration Tests, Reported in This Article (Data Relating to Filter Structure Have Been Determined through X-Ray Microtomography on a 30-ppi-Grade Filter from Supplier C)

CFF

\begin{tabular}{|c|c|c|c|c|c|c|}
\hline \multicolumn{2}{|c|}{ Grade: 30 ppi } & \multicolumn{3}{|c|}{ Fluid } & \multicolumn{2}{|c|}{ Inclusions } \\
\hline$\varepsilon(\mathrm{Pct})$ & $d_{g}(\mu \mathrm{m})$ & $u_{s}\left(\mathrm{~cm} \cdot \mathrm{s}^{-1}\right)$ & $\mu(\mathrm{Pa} \cdot \mathrm{s})$ & $\rho\left(\mathrm{kg} \cdot \mathrm{m}^{-3}\right)$ & $\rho_{p}\left(\mathrm{~kg} \cdot \mathrm{m}^{-3}\right)$ & $d_{p}(\mu \mathrm{m})$ \\
\hline 79 & 1500 & 1 & $1.3 \cdot 10^{-3}$ & 2360 & 3200 & 50 \\
\hline
\end{tabular}

Table IV. Deposition Mechanisms, Definitions, and Values of Relevant Adimensional Numbers

\begin{tabular}{lllll}
\hline Direct Interception & Inertial Impaction & Sedimentation & Surface Forces & Brownian Motion \\
\hline$N_{R}=\frac{d_{p}}{d_{g}}$ & $N_{\mathrm{St}}=\frac{\rho_{p} d_{p}^{2} u_{s}}{18 \mu d_{g}}$ & $N_{G}=\frac{\left(\rho_{p}-\rho\right) d_{p}^{2} g}{18 \mu u_{s}}$ & $N_{\mathrm{Lo}}=\frac{4 H}{9 \pi \mu d_{p} u_{s}}$ & $\mathrm{Pe}=\frac{6 \pi \mu u_{s} d_{p}^{2}}{k T}$ \\
0.03 & $2 \cdot 10^{-3}$ & 0.09 & $4 \cdot 10^{-7}$ & $4 \cdot 10^{7}$ \\
\hline
\end{tabular}

The two preponderant deposition mechanisms are direct interception and sedimentation. The inertial effects are weak and, consequently, neglected. Although surface forces control the adhesion of inclusions to the filter surface, these forces remain negligible compared to hydrodynamic forces, when the inclusions flow inside the porous medium: the inclusion trajectories are not affected by the surface forces until they contact the filter walls. The Brownian motion is negligible compared to the convective motion of inclusions; this is because the trajectory of inclusions in liquid metal is only slightly affected by the Brownian motion. Finally, because the mean diameter of the pore windows is an order of magnitude greater than the mean diameter of the inclusions, it may be established that the contribution of straining remains negligible in the absence of clogging.

Typical capture sites associated with the preponderant deposition mechanisms mentioned here can be seen in Figure 11. This figure shows a lengthwise cut of the top part of filter B2. The presence of the massive inclusions captured through direct interception and sedimentation should be noted, on the one hand, as should the presence of the oxide skins captured by interception, on the other hand.

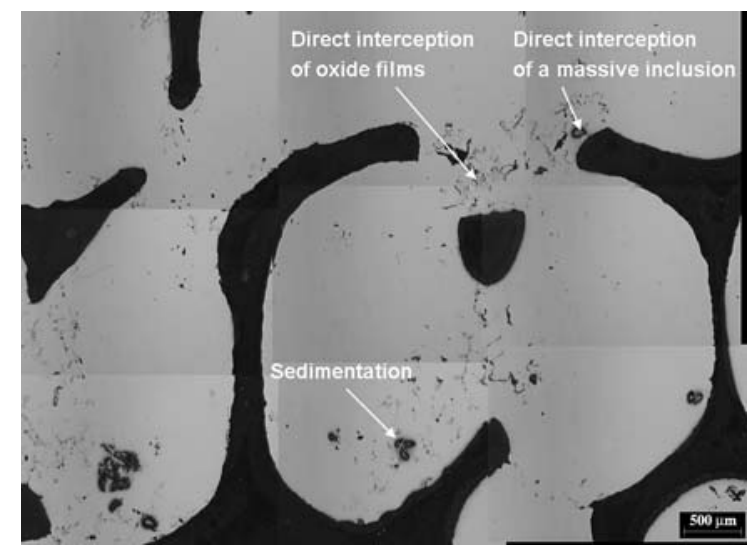

Fig. 11-Lengthwise metallographic cut of the filter in test B2: captures through direct interception and sedimentation.

\section{B. Effect of Interception and Gravitational Numbers}

It seems rather difficult to interpret the relative difference between the average filtration efficiencies (based on the N20) measured in trials A, B1, and B2 and reported in Section III-B (Table II). Indeed, several operating parameters (in particular, the filter grade and filtration velocity) vary between trial A and trials $\mathrm{B} 1$ and B2 (B1 and B2 are characterized by the same operating conditions).

It is generally expected that the filter grade is the main parameter that controls the filter efficiency. However, in the trials discussed here, despite the finer grade, the efficiency is lower for the 50-ppi filter (trials B1 and B2) than for the 30-ppi grade (trial A): the filtration efficiencies are equal to $61 \pm 8 \mathrm{pct}, 60 \pm 8 \mathrm{pct}$, and $77 \pm 4$ pct, respectively.

To explain these results, it should be remembered that the filter coefficient (which is related to the filtration efficiency through Eq. [3]) breaks down into several contributions. Each contribution is associated with a special mechanism for transporting inclusions toward the collecting wall (assuming that these mechanisms are independent). If only the preponderant mechanisms, i.e., interception and sedimentation, in the present study, are taken into account, the filter coefficient $\lambda$ reduces to

$$
\lambda \cong \lambda_{I}+\lambda_{G}
$$

where $\lambda_{I}$ and $\lambda_{G}$ are the interception and sedimentation contributions, respectively. Trajectory analysis models ${ }^{[34]}$ provide the theoretical dependence of $\lambda_{I}$ and $\lambda_{G}$ on $N_{R}$ and $N_{G}$, respectively, for collectors of simple geometry (capillaric or spherical, respectively).

Recently, CFF depth filtration has been studied by CFD, coupled with Lagrangian tracking of the suspended inclusions. ${ }^{[38]}$ These simulations are performed in a representative elementary volume (REV) of the filter. The REV is large compared with the pore size but small compared to the tile scale. The pore network of the REV is provided by X-ray microtomography of a CFF sample. A typical simulation can be sketched as follows: in the first stage, the flow field is computed in the whole complex void space of the filter using a latticeBoltzmann method; in the second stage, the trajectory 
analysis is derived by applying Newton's second law to suspended inclusions in the flowing fluid. Each inclusion is randomly injected upstream and tracked up to its capture site or its filter leaving. The lubrication effect arising when an inclusion approaches a solid surface is taken into account. Adhesion is assumed to be $100 \mathrm{pct}$ efficient. A large number of inclusions are investigated, to provide statistical results. The model provides both microscopic results, such as the initial capture probability density, and macroscopic results, such as the filter coefficient. This work, which has already been presented, ${ }^{[38]}$ will be further detailed in an upcoming article. ${ }^{[42]}$

Figure $12^{[38]}$ reports the variations in the filter coefficient obtained by CFD as a function of the gravitational numbers for two values of the interception number. When $N_{G}>0$ (or $N_{G}<0$ ), the direction of the terminal settling velocity is the same as (or the opposite of) the direction of the main flow. Hence, for inclusions heavier than the melt, $N_{G}>0$ (or $N_{G}<0$ ) corresponds to the downward (or upward) filtration.

The dependence of $\lambda_{I}$ on $N_{R}$ can be derived by sorting $\lambda_{I}$ values at $N_{G}=0$ : the dimensionless interception contribution $\lambda_{I} d_{g}$ is nearly proportional to $N_{R} \cdot{ }^{[38]}$ The $\lambda_{I} d_{g}$ has the same dependence on $N_{R}$ as the capillaric model. ${ }^{[4]}$ Along the same lines, a CFF has a very different behavior compared with a granular bed. Indeed, according to Fitzpatrick's experimental data (reported by Tien in his book ${ }^{[34]}$ ), the interception contribution of a granular bed is proportional to $N_{R}^{2}$ (i.e., the same dependence on $N_{R}$ as the spherical model or the constricted tube model ${ }^{[34]}$ ).

Finally, the analysis of the simulations shows that the dimensionless gravitational contribution $\lambda_{G} d_{g}$ is proportional to $N_{G}$ (when $N_{G}>0$ ). This linear dependence agrees well with the theoretical prediction reported by Tien in Reference 34.

Let us now estimate the expected variation in the interception and sedimentation contribution between trial A and trials B1 and B2, by applying the scaling laws derived earlier.

The connexity numbers by the unit of length of filters $A$ and $B$ are equal to 320 and $370 \mathrm{~m}^{-1}$, respectively. Assuming that the filter structures are homothetic, the

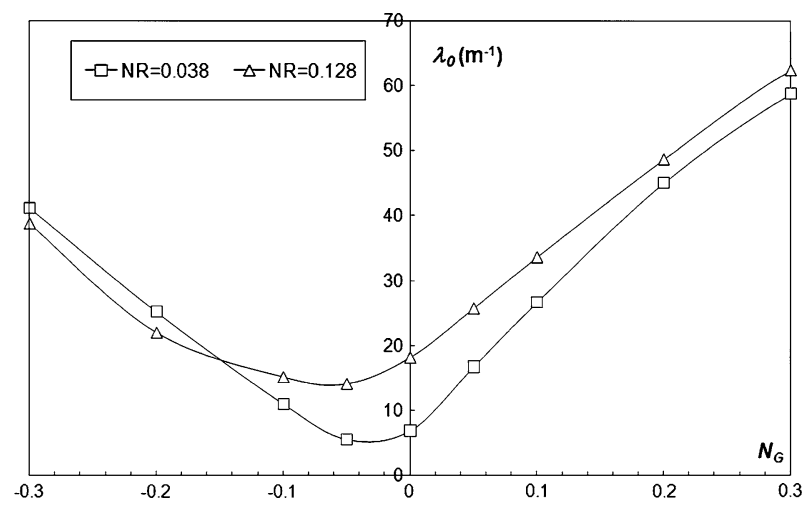

Fig. 12-Dependence of filter coefficient on gravitational number for two values of interception number (results obtained by $\mathrm{CFD}^{[38]}$ ). pore mean diameter decreases by 14 pct between filters $A$ and $B$. Hence, it is expected that the interception number and, consequently, the interception contribution increase by 12 pct between $\mathrm{A}$ and $\mathrm{B}$. In addition, the filtration velocity is equal to $1.3 \mathrm{~cm} \cdot \mathrm{s}^{-1}$ in trial $\mathrm{A}$ and $1.8 \mathrm{~cm} \cdot \mathrm{s}^{-1}$ in trials B1 and B2. This corresponds to an increase in the filtration velocity of 38 pct between test $\mathrm{A}$ and tests B1 and B2. This results in a decrease in the gravitational number and, consequently, the sedimentation contribution by 28 pct. Depending on the absolute value of the interception and gravitational numbers and on the proportionality coefficients that are implicitly present in the scaling laws, the increase in the sedimentation contribution may explain why the efficiencies measured during tests $\mathrm{B} 1$ and $\mathrm{B} 2$ are lower than those measured in test A.

This calculation shows how the mathematical modeling and the numerical simulations throw light on the experimental results and can provide a deeper understanding.

\section{Coexistence of Two Populations of Inclusions}

It is asserted in Section II that the liquid aluminum entering the filtering bowl contains two kinds of inclusions: intentionally added massive inclusions (alumina-based in trials $\mathrm{A}, \mathrm{B} 1$, and $\mathrm{B} 2$ and $\mathrm{SiC}$ in trials $\mathrm{C} 1$ and $\mathrm{C} 2$ ) and oxide films that form as soon as liquid aluminum is in contact with air. However, the relative weight of each inclusion population is not known. This information can be obtained for trials $\mathrm{C} 1$ and $\mathrm{C} 2$ by comparing the LiMCA measurements (which analyze the population of nonconductive inclusions: massive ones and films) with the metallographic counting data.

The LiMCA provides the particle size distribution of suspended inclusions in liquid aluminum at the filter inlet: the $N 20, N 40$, and $N 60$ values obtained at the tilting furnace exit after seeding are approximately 50, 1, and $0.5 \mathrm{k} / \mathrm{kg}$, respectively. The inclusion size at the filter inlet, which is generally less than $40 \mu \mathrm{m}$, should be noted: therefore, the size distribution of inclusions in molten metal substantially differs from the size distribution of artificial silicon carbide inclusions prior to seeding. The latter ranges between 25 and $100 \mu \mathrm{m}$; the number-related fractions over 40 and $60 \mu \mathrm{m}$ are approximately 75 and 50 pct, respectively; and the numberrelated mean diameter is $50 \mu \mathrm{m}$.

In trials $\mathrm{C} 1$ and $\mathrm{C} 2$, the inclusion level at the filter exit remains very low throughout the filtration process: the $N 20$ is lower than $1 \mathrm{k} / \mathrm{kg}$, and the $N 40$ and $N 60$ are lower than $0.1 \mathrm{k} / \mathrm{kg}$. Hence, the major part of the inclusions is captured within the filter.

On the other hand, as presented in Section III-C, the $\mathrm{SiC}$ inclusions have been counted on each transverse cut of the filters used in tests $\mathrm{C} 1$ and $\mathrm{C} 2$. This count permits estimation of the order of magnitude of the total number of $\mathrm{SiC}$ inclusions captured in the $\mathrm{C} 1$ or $\mathrm{C} 2$ filters (assuming that the $\mathrm{SiC}$ inclusions are narrow spheres with a diameter equal to $50 \mu \mathrm{m}$ ). From the total weight of filtered aluminum during each test, the order of magnitude of the mean density of $\mathrm{SiC}$ inclusions per kilogram of liquid aluminum at filter inlet can be 
calculated, i.e., approximately $0.5 \mathrm{k} / \mathrm{kg}$. Thus, artificial inclusions represent, at most, a small percentage of the total inclusion concentration measured by the LiMCA counter upstream of the filter. Based on this assessment, it is concluded that the inclusions in trials $\mathrm{C} 1$ and $\mathrm{C} 2$ are primarily oxide skins. According to LiMCA measurements, oxide skins generally have a diameter (as seen by LiMCA) of less than $40 \mu \mathrm{m}$. It should be noted that these conclusions are certainly valid for these studies, ${ }^{[21-23,29,31,32]}$ in which a high inclusion loading is achieved by stirring: it is expected that most of the inclusions are oxide skins that are generated and incorporated in the melt by stirring.

\section{Interpretation of Nonmonotonous Trend of Filter Coefficient Variations}

In Section III-B, variations in the filter coefficient in trial $\mathrm{A}$ and trials $\mathrm{B} 1$ and $\mathrm{B} 2$ (derived from LiMCA measurements) as a function of the inclusion diameter (Figure 6) have been reported. It has been observed that the filter coefficient is high for low diameter values (close to $20 \mu \mathrm{m}$ ), decreases with an increasing inclusion diameter, reaches a minimum for a diameter value close to $30 \mu \mathrm{m}$, and then increases again.

This nonmonotonous aspect (in particular, the decreasing part) is amazing because, in the CFF depth filtration mode, the two preponderant capture mechanisms, i.e., direct interception and sedimentation, are increasing functions of the inclusion diameter (other parameters being set).

As mentioned in Section I, some authors ${ }^{[24,28]}$ already noticed the nonmonotonous trend of the filtration efficiency variations (or equivalently, of the filter coefficient variations). These authors report a minimum of filtration efficiency for inclusion sizes of approximately $50 \mu \mathrm{m}$. They attributed this tendency to the capture, aggregation, and subsequent release of inclusions in the CFF.

However, in the present experiments, this sketch is not very probable, because more than 95 pct of the foam filter depth (i.e., the filter bottom part) operates in the initial stage of filtration: the captured inclusions are isolated and the only aggregates identified on the ground sections (in the filter bottom part) formed during the seeding of the liquid metal in the tilting furnace. Moreover, the present experiments have been performed on a pilot with a very controlled metal flow rate. Consequently, the release of inclusions generally induced by variations in filtration velocity or vibrations is minimized.

Here, the nonmonotonous trend of the filter coefficient variations can be explained by the coexistence of two populations of inclusions with relative weights that vary with diameter (as measured by LiMCA): the first one is by far the most numerous inclusion type for diameters over $30 \mu \mathrm{m}$, the second one for diameters less than $25 \mu \mathrm{m}$. The first population corresponds to massive inclusions intentionally added into the liquid metal during the seeding phase. The second corresponds to oxide skins generated and nonintentionally incorporated during the molten metal bath seeding and homogenizing phases.

The oxide skins have an apparent volume substantially larger than their absolute volume, because they are generally configured in the form of a very thin tangled film. The volume determined by LiMCA necessarily lies between the two extremes; it is assumed to be significantly smaller than the apparent volume of the oxide skins.

Knowing that direct interception is related to the apparent diameter of the inclusion and, hence, its apparent volume and not its absolute volume, the capture probability of an oxide skin would be significantly higher than that of a massive alumina inclusion with the same absolute volume. This hypothesis is an explanation for the high filter coefficient values measured for the 15- to $20-\mu \mathrm{m}$ diameter interval in test $\mathrm{A}$ and tests B1 and B2. In addition, the fact that the direct interception mechanism is not dependent on the filtration velocity would explain that the filter coefficient values for the 15- to 20- $\mu \mathrm{m}$ diameter interval are close to each other in test A and tests B1 and B2. The decrease in the filter coefficient when the diameter measured by LiMCA increases by a value less than approximately $30 \mu \mathrm{m}$ would be related to the decrease in the relative weight of the oxide skins. For diameters over $30 \mu \mathrm{m}$, massive inclusions predominate and the filter coefficient increases with the diameter measured by LiMCA.

\section{E. Determination of Initial Filter Coefficient from Captured Inclusion Density Profile}

On the basis of successive transverse metallographic cuts carried out on filters from tests $\mathrm{C} 1$ and $\mathrm{C} 2$ and reported in Section III-C, it is possible to determine the initial filter coefficient. It is relevant to focus on the bottom part of the filters, because it still operates in the initial stage of depth filtration at the end of the experiments. As a first step, the density profile of the isolated $\mathrm{SiC}$ inclusions has been derived from the raw data (reported in Figure 10 for trial $\mathrm{C} 1$ ), using an appropriate averaging procedure. Next, the initial filter coefficient can be evaluated from the captured inclusion density profile $n(z)$, because

$$
n(z) \propto \exp (-\lambda z)
$$

Figure 13 presents the variations in the dimensionless density of isolated $\mathrm{SiC}$ inclusions (normalized by the mean density $n_{a v}$ of isolated $\mathrm{SiC}$ inclusions in the filter)

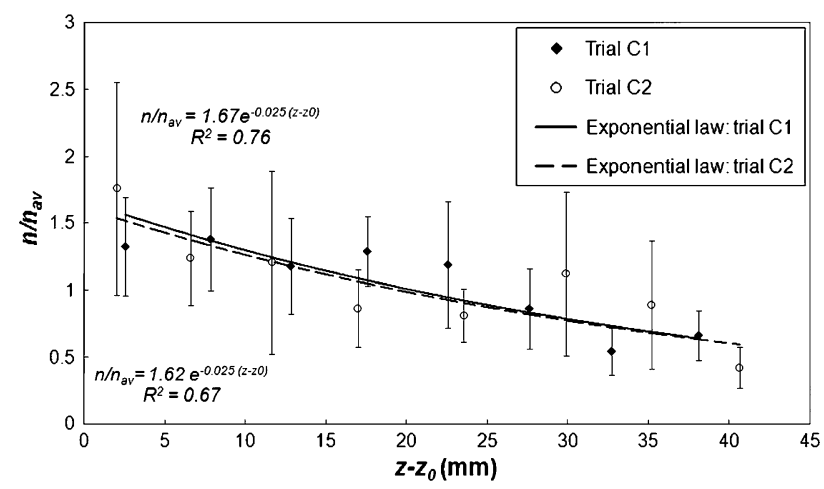

Fig. 13-Estimation of the filter coefficient from metallographic analysis. 
as a function of the depth of the filter $(z$ is counted from the filter entrance and $z_{0}$ is the thickness of the top part of the filter), for the $\mathrm{C} 1$ and $\mathrm{C} 2$ trials. The experimental points are well fitted by an exponential law. The argument of the exponential law is the filter coefficient. It is equal to $\lambda=25 \pm 4 \mathrm{~m}^{-1}$ and $\lambda=25 \pm 5 \mathrm{~m}^{-1}$ for $\mathrm{C} 1$ and $\mathrm{C} 2$, respectively. It should be noted that the filter coefficient values provided by trials $\mathrm{C} 1$ and $\mathrm{C} 2$ are narrow, confirming that the repeatability of the experimental setup is satisfactory. These values lie within the range of the experimental values given in the literature (Figure 2): for the same filter grade, these values generally lie between $\lambda=17$ and $28 \mathrm{~m}^{-1}$. They are also close to the value of the filter coefficient, i.e., $\lambda=$ $25 \pm 4 \mathrm{~m}^{-1}$, as measured by LiMCA for the diameter range 40 to $60 \mu \mathrm{m}$ in trial A (performed with a larger filtration velocity, i.e., $1.3 \mathrm{~cm} \cdot \mathrm{s}^{-1}$, through a filter of the same grade but from a different supplier). In addition, these values are consistent with the results of the CFD simulations. ${ }^{[38]}$ Thus, the filter coefficient (calculated for a 30-ppi filter grade from the same supplier as for trials $\mathrm{C} 1$ and $\mathrm{C} 2$ and for the same filtration velocity, i.e., $0.9 \mathrm{~cm} \cdot \mathrm{s}^{-1}$ ) is estimated at $\lambda=24 \mathrm{~m}^{-1}$ for spherical inclusions of $50 \mu \mathrm{m}$ in diameter and of same density as silicon carbide. Based on the inclusion distribution between the top and bottom parts of the $\mathrm{C} 1$ filter, i.e., 15 and 85 pct, respectively, the filtration efficiency of the top part may be estimated at 8 pct and the filtration efficiency of the bottom part at 70 pct. Therefore, the total efficiency of $\mathrm{C} 1$ filter for $\mathrm{SiC}$ inclusions can be derived $(E=72 \mathrm{pct})$. It should be noted that the top part of the filter, where the depth filtration is enhanced by the trapped oxide films, is more efficient (per filter unit of length) than the bottom part. Thus, the filter coefficient in the top part (derived from efficiency) is equal to $39 \mathrm{~m}^{-1}$, compared to the filter coefficient in the bottom part, which is equal to $25 \mathrm{~m}^{-1}$.

It should be noted that the filtration efficiency measured from the transverse metallographic cuts (that relates only to $\mathrm{SiC}$ inclusions) is significantly lower than the filtration efficiencies measured in trials $\mathrm{C} 1$ or $\mathrm{C} 2$ using the LiMCA. These efficiencies, often larger than 95 pct, are mainly associated with oxide skins, which represent approximately 99 pct of the suspended inclusions in trial $\mathrm{C} 1$ (Section C). As mentioned earlier (Section D), this difference can be explained by the fact that, based on equal weight, an oxide skin has an equivalent diameter much greater than a massive inclusion of identical chemistry, leading to a significant increase in the interception contribution. In addition, it seems that clogging affects the capture of oxide films more than the capture of massive inclusions. One possible reason for this could be that, as clogging increases at the filter entrance, pore constrictions become narrower and oxide skins can be captured by straining (cake filtration).

\section{CONCLUSIONS}

In order to study and quantify the mechanisms acting during liquid aluminum filtration through CFFs, a filtration pilot has been designed. Its main characteristic is the fact that the metal can calmly solidify in the filter, preventing the inclusions from release and spatial redistribution. The tile can then be cut lengthwise and transversally for metallographic observations of the inclusions at various depths. Furthermore, the pilot is instrumented with two Coulter counters, one before and one after the filter.

Four trials have been reported in the present article. They have been performed on alumina-based filters the geometric characteristics of which (measured by stereometry) are relatively similar. Before entering the filter bowl, the melt is artificially seeded with massive inclusions (either alumina-based or silicon carbide). Hence, liquid aluminum contains two kinds of inclusions: intentionally added massive ones and oxide films that form as soon as liquid aluminum is in contact with air.

The theoretical analysis of the depth filtration of massive inclusions shows that there are two preponderant deposition mechanisms, i.e., direct interception and sedimentation. Capture sites associated with interception and sedimentation have been identified on a lengthwise cut of nondrained filters. The preponderant mechanisms explain qualitatively the effect of the operating conditions (the geometric characteristics of the filter and filtration velocity) on the filter coefficient.

In the case of the trials performed with the seeding of $\mathrm{SiC}$ inclusions, the intentionally added massive inclusions concentration could be derived (from the metallographic analysis of the nondrained filter) and compared to the total inclusion concentration measured by the Coulter counter; this reveals that, in these trials, the intentionally added inclusions represent at most a few percents of the total inclusion concentration. Hence, it is expected that, in the four trials reported in the present article, oxide skins represent a significant part of the suspended inclusions in the melt.

The coexistence of these two populations of inclusions may explain the filter coefficient variations observed in the present experiments: the filter coefficient surprisingly decreases with an increasing inclusion diameter, reaches a minimum for a diameter value close to $30 \mu \mathrm{m}$, and then slightly increases. Indeed, it is expected that the oxide skins are the most numerous inclusion type for diameters less than $25 \mu \mathrm{m}$, whereas massive inclusions are the most numerous inclusion type for diameters over $30 \mu \mathrm{m}$. In addition, the oxide skins have an apparent volume much larger than their absolute volume (contrary to massive inclusions), which leads to an enhanced interception contribution to the filter coefficient and, consequently, to the larger value of the filter coefficient.

Finally, the analysis of successive transverse metallographic cuts through spent filters permits verification (for the first time, both in the case of liquid metal filtration and in the case of liquid filtration, through open-pore foam) that the density of the captured inclusions decreases exponentially between the filter inlet and the filter outlet (except, perhaps, for the first $2 \mathrm{~mm}$ ): this features a depth filtration mode. The initial filter coefficient can be derived from the density profile: it is equal to $25 \mathrm{~m}^{-1}$ for a 30 -ppi-grade filter (with a 
specific surface area of $1610 \mathrm{~m}^{-1}$ ), with respect to $\mathrm{SiC}$ inclusions with a mean diameter of $50 \mu \mathrm{m}$, based on an average filtration velocity of $0.9 \mathrm{~cm} \cdot \mathrm{s}^{-1}$.

Ultimately, our objective is to compare systematically the experimental data derived from the present work with the results furnished by the CFD filtration simulation code that we concurrently developed ${ }^{[38,42]}$ and, in addition, to develop a specific experimental device to gain deeper insight into the behavior of oxide films in liquid aluminum.

\section{ACKNOWLEDGMENTS}

This research was supported by the Centre de Recherches de Voreppe (ALCAN) and the French Ministry of the Economy, Finance, and Industry, as part of the CIPAL project (Project No. 03490 6014), Réseau de Recherche et d'Innovation Technologiques Matériaux et Procédés. The authors express their gratitude to J. Trubuil and R. Rey Flandrin for their technical contribution to the project.

\section{TABLE OF SYMBOLS}

$d_{p}$
$d_{g}$
$E$
$g$
$\mathrm{H}$
$\mathrm{k}$
$L$
$n$
$n_{a v}$

inclusion mean diameter

pore mean diameter

filter efficiency

gravitational acceleration

$\mathrm{H} \quad$ Hamaker's constant (of the order of $10^{-19} \mathrm{~J}$ )

k Boltzmann's constant

$L \quad$ filter depth

$n$ number of inclusions per unit of volume

$n_{a v} \quad$ number of inclusions per unit of volume averaged in the whole depth of the filter

$N 20 \quad$ number of inclusions larger than $20 \mu \mathrm{m}$ per kilogram of aluminum alloy

$N 20_{i} \quad$ number of inclusions larger than $20 \mu \mathrm{m}$ per kilogram of aluminum alloy at the filter inlet

$N 20_{o} \quad$ number of inclusions larger than $20 \mu \mathrm{m}$ per kilogram of aluminum alloy at the filter outlet

$N_{G} \quad$ gravitational number

$N_{\text {Lo }} \quad$ London number

$N_{R} \quad$ interception number

$N_{\text {St }} \quad$ Stokes number

$\mathrm{Pe} \quad$ Péclet number

$Q_{m} \quad$ mass flow rate

$S \quad$ filter surface

$T \quad$ absolute temperature

$u_{s} \quad$ superficial velocity

$z \quad$ coordinate in the depth of the filter

$z_{0} \quad$ thickness of the top part of the filter

$\varepsilon \quad$ filter porosity

$\lambda$ filter coefficient

$\lambda_{G} \quad$ gravitational contribution to the filter coefficient

$\lambda_{I} \quad$ interception contribution to the filter coefficient

$\mu \quad$ fluid dynamic viscosity

$\rho \quad$ fluid density

$\rho_{p} \quad$ inclusion density

\section{REFERENCES}

1. C. Conti: Doctoral Thesis, Faculté Polytechnique de Mons, Mons, Belgium, 1983.

2. F. Frisvold: Doctoral Thesis, University of Trondheim, Trondheim, Norway, 1990.

3. T.A. Engh: Principles of Metal Refining, 1st ed., Oxford University Press, Oxford, United Kingdom, 1992, pp. 1-35.

4. G.H. Nijhof and R. Van der Laan: in Light Metals Proc., TMS, Warrendale, PA, 1998, pp. 1245-49.

5. L. Katgerman and J. Zuidema: J. Met., 2004, vol. 56, p. 172.

6. J.H. Courtenay, F. Reusch, A. Turchin, D. Erskin, and L. Katgerman: in Light Metals Proc., TMS, Warrendale, PA, 2008, pp. 645- 47.

7. A.D. Patel and N. El-Kaddah: in Light Metals Proc., TMS, Warrendale, PA, 1997, pp. 1013-18.

8. J.P. Park, A. Morihira, K. Sassa, and S. Asai: Tetsu-to-Hagané, 1994, pp. 31-36.

9. O.I. Raychenko, V.P. Popov, O.V. Derev'yanko, T.I. Istomina, and A.I. Repenko: J. Mater. Synth. Process., 2002, vol. 10 (6), pp. $345-51$.

10. P. Marty and A. Alemany: Metallurgical Applications of Magnetohydrodynamics, Proc. Symp. Int. Union of Theoretical and Applied Mechanics, Cambridge, United Kingdom, Sept. 6-10, 1982, The Metals Society, London, 1984, pp. 245-59.

11. S. Makarov, L. Reinhold, and D. Apelian: IEEE Trans. Magn., 2001, vol. 37 (2II), pp. 1024-31.

12. G.I. Eskin: Adv. Perform. Mater., 1997, vol. 4 (2), pp. 223-32.

13. D.V. Neff and E.P. Stankiewicz: in Light Metals Proc., Metallurgical Society of AIME, Warrendale, PA, 1986, pp. 821-28.

14. K. Hoshino, T. Nishizaka, K. Kakimoto, and T. Yoshida: in Light Metals Proc., TMS, Warrendale, PA, 1996, pp. 833-38.

15. K.J. Brondyke and P.D. Hess: Trans. TMS-AIME, 1974, vol. 230, pp. $1553-56$.

16. D. Apelian and R. Mutharasan: J. Met., 1980, vol. 32 (9), pp. 14-19.

17. J.P. Desmoulin, H. D'Hondt, J.M. Hicter, and P. Netter: in Light Metals Proc., Metallurgical Society of AIME, Warrendale, PA, 1989, pp. 757-67.

18. L.S. Aubrey and J.E. Dore: in Light Metals Proc., TMS, Warrendale, PA, 1993, pp. 1009-20.

19. R.A. Olson, III and L.C.B. Martins: Adv. Eng. Mater., 2005, vol. 7 (4), pp. 187-92.

20. K. Kakimoto, E. Takahashi, Y. Shiraishi, T. Yoshida, and O. Yagishita: in Light Metals Proc., TMS, Warrendale, PA, 1993, pp. 1021-28

21. S. Instone, M. Badowski, and W. Schneider: in Light Metals Proc., TMS, Warrendale, PA, 2005, pp. 933-38.

22. N.J. Keegan, W. Schneider, H.P. Krug, and V. Dopp: in Light Metals Proc., TMS, Warrendale, PA, 1997, pp. 973-82.

23. W. Schneider, H.P. Krug, and N.J. Keegan: 6th Aust. Asian Pacific Conf. on Aluminium Cast House Technology, Sydney, Australia, Minerals, Metals \& Materials Society, Warrendale, PA, 1999, pp. $159-74$.

24. D.D. Smith, L.S. Aubrey, and W.C. Miller: in Light Metals Proc., TMS, Warrendale, PA, 1998, pp. 893-915.

25. L.A. Strom, J.W. Black, R.I.L. Guthrie, and C. Tian: in Light Metals Proc., TMS, Warrendale, PA, 1992, pp. 1093-1100.

26. C. Tian and R.I.L. Guthrie: in Light Metals Proc., TMS, Warrendale, PA, 1993, pp. 1003-07.

27. C. Dupuis and R. Dumont: in Light Metals Proc., TMS, Warrendale, PA, 1993, pp. 997-1002.

28. C. Dupuis, G. Béland, and J.P. Martin: 32nd Ann. Conf. of Metallurgists, Québec City, PQ, Canada, The Metallurgical Society of CIM, Montreal, 1993, pp. 349-58.

29. N.J. Keegan, W. Schneider, and H.P. Krug: in Light Metals Proc., TMS, Warrendale, PA, 1999, pp. 1031-40.

30. R. Mutharasan, D. Apelian, and A. Romanowski: J. Met., 1981, vol. 33 (12), pp. 12-18.

31. N. Towsey, W. Schneider, H.P. Krug, A. Hardman, and N.J. Keegan: in Light Metals Proc., TMS, Warrendale, PA, 2001, pp. 973-77.

32. N. Towsey, W. Schneider, and H.P. Krug: 7th Aust. Asian Pacific Conf. on Aluminium Cast House Technology, Hobart, Australia, TMS, Warrendale, PA, 2001, pp. 125-37.

33. T. Iwasaki: J. Am. Water Works Assoc., 1937, vol. 29, pp. 15911602. 
34. C. Tien: Granular Filtration of Aerosols and Hydrosols, 1st ed., Butterworths, Boston, MA, 1989, pp. 103-38.

35. C. Tian and R.I.L. Guthrie: Metall. Mater. Trans. B, 1995, vol. 26B, pp. 537-46.

36. C. Tian, D. Mazumdar, and R.I.L. Guthrie: Metall. Mater. Trans. B, 1999, vol. 30B, pp. 891-900.

37. E. Laé, H. Duval, C. Rivière, P. Le Brun, and J.-B. Guillot: in Light Metals Proc., TMS, Warrendale, PA, 2006, pp. 753-58.

38. H. Duval, C. Rivière, E. Laé, P. Le Brun, and J.-B. Guillot: in Light Metals Proc., TMS, Warrendale, PA, 2007, pp. 64550 .
39. M. Cooksey, T. Ware, and M.J. Couper: in Light Metals Proc., TMS, Warrendale, PA, 2001, pp. 965-71.

40. N. Eustathopoulos, M.G. Nicholas, and B. Drevet: Wettability at High Temperatures, 1st ed., Pergamon, Oxford, United Kingdom, 1999, pp. 261-82.

41. S.T. Johansen and S. Taniguchi: in Light Metals Proc., TMS, Warrendale, PA, 1998, pp. 855-61.

42. H. Duval, C. Rivière, E. Laé, P. Le Brun, and J.-B. Guillot: unpublished research, 2006.

43. A.C. Payatakes, R. Rajagopalan, and C. Tien: Can. J. Chem. Eng., 1974, vol. 52 (12), pp. 722-31. 